ISSN 1518-3483

Licenciado sob uma Licença Creative Commons

(c) (1)

\title{
Impactos da formação pós-graduada dos professores em escolas portuguesas
}

\author{
The impacts of teachers' post-graduate training in \\ portuguese schools
}

El impacto de la formación de postgrado de los profesores en las escuelas portuguesas

\section{Ana Rita Faria ${ }^{[a]}$, Pedro Guilherme Rocha dos Reis ${ }^{[b]}$, Maria Helena Peralta ${ }^{[b]^{*}}$ \\ [a] Faculdade de Ciências Humanas da Universidade Católica Portuguesa, Lisboa, Portugal \\ [b] Instituto de Educação da Universidade de Lisboa, Lisboa, Portugal}

\section{Resumo}

A investigação apresentada teve como problema central estudar o impacto da Formação Pós-Graduada (FPG) de professores do Ensino Básico (EB) e do Ensino Secundário (ES) em

ARF: Doutora, e-mail: a.rita_faria@hotmail.com

PGRR: Doutor, e-mail: preis@ie.ulisboa.pt

MHP: Doutora, e-mail: hperalta@ie.ulisboa.pt 
dois agrupamentos de escolas em Portugal. Procurámos entender se os professores assumem essa formação como um benefício e de que forma isso se manifesta na melhoria do seu desempenho profissional, das escolas e das aprendizagens dos alunos. Apresentámos, ainda, sugestões para potencializar os efeitos da FPG frequentada por professores.

Palavras-chave: Formação pós-graduada. Professores. Avaliação do impacto. Sugestões.

\begin{abstract}
The main aim of the present study was to focus on the impact of post-graduation education on primary and secondary schoo teachers from two school clusters in Portugal. We sought to find out whether theses teachers perceive their post-graduation experience as an asset and how it is manifested in the improvement of their professional performance, of the respective school and pupils' learning. We also presented suggestions to potentiate the effects of post-graduate training attended by teachers.
\end{abstract}

Keywords: Post graduated education. Teachers. Impact assessment. Suggestions.

\title{
Resumen
}

La investigación presentada tuvo como problema central el estudio del impacto de la Formación Postgraduada (FPG) en un conjunto de profesores de Enseñanza Básica (EB) y Enseñanza Secundaria (ES) en Portugal. Tratámos de entender si los profesores asumen esa formación como un valor añadido y de que forma eso se manifiesta en la mejora de su desempeño profesional, de las escuelas y del aprendizaje de los alumnos. Presentamos otras sugerencias para mejorar los efectos de la FPG asistido por los profesores.

Palabras clave: La formación de postgrado. Profesores. La evaluación del impacto. Sugerencias. 


\section{Introdução ${ }^{1}$}

O presente artigo analisa o impacto da Formação Pós-Graduada (FPG) nos professores que a frequentaram, nas escolas em que exercem funções e na comunidade em que se inserem. Os dados apresentados resultam de uma investigação realizada no âmbito de um doutoramento em Educação, que teve como problema central a construção de conhecimento sobre o impacto da frequência de cursos de pós-graduação - pós-graduação ${ }^{2}$, mestrado ${ }^{3}$ e doutoramento ${ }^{4}$ - num conjunto de professores do ensino básico $(E B)^{5}$ e do ensino secundário $(E S)^{6}$ situados profissionalmente em dois agrupamentos de escolas ${ }^{7}$ em Portugal. Este estudo emergiu de

1 Investigação financiada pela Fundação para a Ciência e Tecnologia (FCT) no âmbito da atribuição de uma bolsa de doutoramento (SFRH/ BD/ 87243/ 2012).

2 Primeiro ano do ciclo de estudos conducente ao grau de mestre. Este ano corresponde à componente curricular do curso de mestrado numa área de especialização.

3 Curso de pós-graduação, cujo grau académico é atribuído por uma instituição de ensino superior, na sua maioria Universidades, podendo a duração ir de 2 a 5 anos. 0 mestrado situa-se entre a licenciatura e o doutoramento. Este curso termina, geralmente, com a apresentação de uma dissertação sobre um tema inserido na área de especialização. Concluído o curso de mestrado é concedido o grau de mestre na área estudada pelo indivíduo. Em Portugal, tal como noutros países, este curso encontra-se já integrado nas licenciaturas como consequência do Processo de Bolonha.

4 Curso de pós-graduação, cujo grau académico é atribuído, à semelhança do mestrado, por uma instituição de ensino superior, tendo uma duração que pode ir de 2 a 5 anos. 0 doutoramento tem como objetivo certificar o indivíduo para o desenvolvimento de investigação numa área específica escolhida. Este curso termina, na maioria dos casos, com a apresentação pública de uma tese realizada no âmbito da área de especialização com recurso a trabalho de natureza empírica. Concluído o curso de doutoramento é concedido o grau de doutor na área estudada pelo indivíduo.

5 O Ensino Básico compreende três ciclos: 1ำ ciclo que tem a duração de quatro anos - do 10 ao 4 o ano de escolaridade - frequentado por crianças a partir dos 6 anos de idade; 2 ciclo que contempla o 5 e 6 o anos de escolaridade normalmente frequentado por crianças entre os 10 e os 11 anos de idade; 3 으 ciclo que integra o 7으, 8 ㅇ e 9 음 anos de escolaridade frequentado, maioritariamente, por crianças entre os 12 e os 14 anos de idade.

6 O Ensino Secundário tem a duração de três anos - 10ำ, 11ำ $12^{\circ}$ anos-frequentados, normalmente, por jovens adolescentes entre os 15 e os 17 anos de idade.

7 Os agrupamentos de escolas são unidades organizacionais do sistema educativo português, com órgãos de administração e gestão próprios. Integram estabelecimentos de educação do ensino préescolar e de um ou mais níveis e ciclos de ensino partilhando de um projeto pedagógico comum. 
uma investigação realizada a nível nacional que tinha como objetivo caracterizar e compreender a distribuição dos docentes pós-graduados e as suas implicações na melhoria do ensino e da escola. Desta forma, foi nossa intenção estudar em profundidade as realidades identificadas em dois agrupamentos. Procurou-se, então, compreender se a FPG é reconhecida pelos professores como um benefício e em que medida isso se traduz na melhoria do seu desempenho profissional, das escolas e, em última instância, das aprendizagens dos alunos. Após compreendermos o impacto da FPG, deixamos sugestões sobre como potenciar esta mesma formação.

\section{Breve quadro teórico: currículo}

Afirmamos o currículo como um dos principais conceitos em que se alicerça a prática educativa, possibilitando a compreensão da forma como a prática se desenvolve e operacionaliza nos diferentes contextos.

O modo como cada indivíduo entende a dinâmica de ensino-aprendizagem leva-nos às muitas definições existentes de currículo (e.g. Gress \& Purpel, 1978; Lewis, 1902; Doyle, 1992; Carr, 1993; Roldão, 1999, 2005; Sacristán, 2000; Zabalza, 2001; Pacheco, 2003; Peralta, 2005; Jesus, 2008). No entanto, todas as definições variam no que se refere à sua abrangência e precisão (ESTRELA, 2011). Considerando, então, as inúmeras definições possíveis a conceção adotada neste estudo compreende o currículo como um conjunto de aprendizagens realizadas e de competências desenvolvidas pelo aprendente resultantes de um processo de ensino-aprendizagem formal, contextualizado histórica e socialmente. Posicionámo-nos numa perspetiva que reflete o desenvolvimento curricular e o seu impacto, sendo que ao analisarmos o currículo dos cursos de FPG avaliamos se e de que forma aquilo que os docentes que frequentaram estes cursos fazem poderá ser uma consequência do próprio currículo experienciado. 


\section{Formação Pós-Graduada}

Para além das responsabilidades de cada docente associadas ao seu domínio do saber enquanto transmissor de conhecimento, cada professor tem hoje responsabilidades ao nível psicossocial e psicossociológico no âmbito da intervenção educativa (CUNHA, 2008). Com o aumento e diversificação das atividades exigidas aos professores, o exercício da sua profissão obriga a uma aposta na formação e a uma atualização de conhecimentos e técnicas e do desenvolvimento das suas competências (LEITE, s.d.). A FPG surge, então, como uma formação essencial para o desempenho de funções específicas (CAMPOS, 1995), assumida como uma formação de maior qualidade e mais profunda que a formação inicial permitindo ultrapassar os campos didáticos trabalhados por cada professor no decurso da sua formação inicial (LEITE, 2005).

Neste âmbito, as variações demográficas e a evolução tecnológica fizeram com que os números que se referem ao ensino e à aprendizagem se alterassem traduzindo-se no crescimento da procura de FPG e na necessidade de criar alterações a esta formação visando a requalificação da população (POUZADA, et al., 2003).

A oferta de FPG no campo da educação iniciou-se nos anos oitenta desencadeada por motivos como o interesse em aprofundar conhecimentos, a aquisição de um novo grau académico e a progressão na carreira, tal como o desenvolvimento de competências para o desempenho de funções específicas enquanto docentes ou outras no contexto educativo (CAMPOS, 1995).

\section{Avaliação do Impacto da Formação}

A avaliação de cursos pós-graduados e do seu impacto resulta do aumento da oferta formativa e da necessidade de compreender como se desenvolve a interação entre a formação, a investigação e as práticas dos professores (POMBO \& COSTA, 2009). 
Considerando que a formação deve estar associada ao desenvolvimento profissional e obrigar a uma especialização que responda às necessidades resultantes dos novos perfis profissionais, a avaliação do impacto deverá ser considerada uma oportunidade de promover a reflexão sobre estas questões (PEREIRA \& COSTA, 2005.

Reconhecemos que avaliar o impacto da formação é apenas avaliar uma das dimensões contempladas numa avaliação da formação (PEREIRA \& COSTA, 2005). Importa, assim, definir impacto como as consequências em determinada realidade passíveis de serem observadas, direta ou indiretamente, com uma durabilidade significativa e que se assumem como contributo(s) para a modificação dessa mesma realidade (ROLDÃO, et al., 2000). Contudo, ao falarmos de impacto e das implicações na sua relação com os sujeitos envolvidos é fundamental distinguir diferentes tipos de impacto: direto ou indireto e positivo, nulo ou negativo. O primeiro tem repercussões imediatas na audiência, pelo que é possível medi-lo com o recurso a indicadores observáveis ou a uma descrição pormenorizada do que se observa. O impacto indireto tem influência sobre as audiências, mas não pode ser diretamente comprovado, visto que as transformações daqui resultantes se dão, por exemplo, ao nível do quadro teórico que fundamenta as suas práticas. Por sua vez, o impacto positivo é entendido realmente como benéfico para a audiência; contudo o que é favorável para um determinado público poderá tornar-se negativo para outro (CRUZ, POMBO \& COSTA, 2008). Assim, para se fazer uma avaliação do impacto da formação, é necessário procurar indicadores que explicitem os efeitos que determinada formação teve no desenvolvimento e desempenho daqueles que a frequentaram (PEREIRA \& COSTA, 2005).

Em suma, a avaliação é um elemento fundamental e uma prática essencial para a melhoria dos programas, das instituições, das pessoas e da sociedade, apelando a uma discussão ativa sobre os fenómenos (FERNANDES, 2010). 


\section{Síntese das fases da investigação}

O estudo realizado, de natureza qualitativa situado num paradigma de investigação interpretativo (LESSARD-HÉBERT, GOYETTE \& BOUTIN, 2005; COHEN, MANION \& MORRISON, 2006), foi organizado em cinco fases, sendo a revisão de literatura um procedimento transversal a todo o processo. A primeira fase implicou a leitura e análise dos questionários que tinham sido aplicados no estudo mais amplo a nível nacional. Os resultados obtidos por meio da aplicação dos instrumentos no âmbito do estudo nacional levaram-nos para a descrição e análise de alguns perfis curriculares ${ }^{8}$ de cursos de FPG mais frequentados pelos professores em Portugal, recorrendo à análise documental, constituindo esta a segunda fase do estudo. O trabalho empírico aconteceu na terceira fase contemplando a realização de dois estudos de caso. Nesse momento foram aplicados novos questionários, visando a identificação dos pós-graduados e a caracterização dos docentes respondentes. Após a identificação dos professores com FPG foram realizadas entrevistas semi-diretivas a estes docentes e àqueles que ocupam cargos de liderança. No caso 1 foram realizadas 36 entrevistas a professores com FPG e 16 a professores com cargos de liderança, dos quais 5 tinham com FPG; no caso 2 foram realizadas 10 entrevistas a professores com FPG e 4 a líderes, sendo que 2 eram também pós-graduados. Seguiu-se, novamente, a descrição e análise de perfis curriculares, desta vez de cursos frequentados por alguns dos entrevistados (15 cursos).

Os dados recolhidos ao longo de todo o estudo foram submetidos a uma análise de conteúdo, resultando numa quarta fase destinada a uma reflexão, articulação e integração destes dados de forma a permitir compreender o impacto da FPG dos professores nos três níveis de análise. A quinta e última fase foi destinada à criação de propostas para as universidades e para as escolas com o objetivo de potenciar o impacto da FPG.

8 A descrição e análise dos perfis curriculares implicou compreender quais as áreas, os objetivos, as finalidades, as competências, os conteúdos, as metodologias, as atividades, o tipo de trabalho esperado (teórico ou prático), os resultados esperados, a avaliação e o regime das FPG mais escolhidas pelos professores num período pré e/ou pós-Bolonha. 


\section{O impacto da FPG}

Considerando como objetivo principal da investigação conhecer e analisar o impacto da FPG, situando este impacto em três níveis da ação profissional dos docentes - na sala de aula (micro-impacto), na escola (meso-impacto) e nas práticas investigativas e educativas (macro-impacto) - através da realização das entrevistas aos diferentes participantes, acabou por emergir um quarto nível associado aos efeitos pessoais (auto-impacto), tornando-se, assim, essencial definir também o impacto da FPG ao nível pessoal. Torna-se importante a ideia de que ao falarmos de impactos da FPG falamos de impactos possíveis, visto que não é por um professor ter frequentado uma FPG que sofrerá todos os efeitos referidos.

\section{Impacto pessoal (auto-impacto)}

Os cursos pós-graduados revelam-se enquanto processos com efeitos ao nível do desenvolvimento pessoal e profissional. São formações com consequências positivas no que respeita ao enriquecimento e à realização pessoal e profissional como é visível nos discursos dos diferentes entrevistados (e.g. "A coisa mais importante que eu fiz na minha vida, por mim, a seguir a ter tirado uma licenciatura, foi precisamente ter voltado" - professor A, ensino secundário, caso 2). A FPG tem também consequências positivas na formação, na conquista e na valorização pessoal, assim como na atualização e/ ou na aquisição de novos conhecimentos como podemos constatar pelo discurso de um dos professores entrevistados "eu era capaz ao fim de tantos anos de prisão intelectual conseguir desenvolver, fazer demostrações, perceber coisas de um nível bastante elevado" (prof. A, $3^{\circ}$ ciclo do EB, caso 1 ).

Ao nível pessoal, a FPG manifesta-se como um benefício para a confiança, autoestima, motivação e preparação daqueles que a frequentaram, havendo ainda a possibilidade de revelar docentes mais organizados e rigorosos (e.g. "fiquei mais forte e mais preparada" - prof. B, $1^{\circ}$ ciclo 
do EB, caso 1; "trouxe-me uma autoestima maior, mais confiança e uma outra perspetiva sobre mim próprio" - prof. C, $3^{\circ}$ ciclo do EB, caso 1 ; “a pós-graduação deu-me uma grande bagagem para eu poder sentir aquela força toda e aquela motivação toda para seguir em frente, para tomar decisões e fazer o que me aparecia na frente" - prof. B, $2^{\circ}$ ciclo do EB, caso 2; "tornou-me realmente mais organizada, mais de planeamento e mais rigorosa em algumas coisa" - prof. C, $3^{\circ}$ ciclo do EB, caso 2). Os efeitos da FPG manifestam-se igualmente no desenvolvimento de profissionais mais preparados, mais capazes, mais resilientes, com perspetivas diferentes sobre si e sobre os outros. A FPG possibilita abrir horizontes e um enriquecimento cultural enquanto resultado do aumento do gosto pelo conhecimento, da vontade de continuar a estudar, a investigar e de querer saber mais: "Num plano pessoal o benefício que ficou desta formação foi claramente a vontade de lá voltar" (prof. D, $2^{\circ}$ ciclo do EB, caso 2). Importa neste âmbito mencionar que certos impactos referidos como pessoais não deixam de ter consequências ao nível profissional, como sendo a mudança de atitudes e de práticas do dia-a-dia, uma maior sensibilidade e capacidade para a tomada de decisão e para a justificação das práticas. Os cursos pós-graduados têm também repercussões no enriquecimento do currículo do professor e na progressão na carreira quando estipulada na legislação em vigor.

\section{Impacto na sala de aula (micro-impacto)}

Na sala de aula, os cursos pós-graduados frequentados por professores têm consequências na mudança de práticas e na alteração ou adoção de novos recursos (e.g. "muitos dos trabalhos que eu consulto na Faculdade ajudam-me a mudar práticas na sala de aula" — prof. D, ensino secundário, caso 1; "agora posso e sei introduzir novas tecnologias e ensinar com elas os alunos" - prof. E, $1^{\circ}$ ciclo do EB, caso 2). A realização de FPG constitui um fator impulsionador da realização de mais trabalhos práticos e de discussão, permitindo ainda, através das diferentes teorias 
abordadas, justificar as práticas diárias e refletir sobre as metodologias adotadas como podemos verificar através das partilhas feitas por alguns dos entrevistados de que são exemplo as afirmações de dois professores envolvidos no estudo: "Tudo o que eu aprendi nesta pós-graduação consegui inserir dentro das minhas aulas, tudinho" (prof. $\mathrm{B}, 1^{\circ}$ ciclo do $\mathrm{EB}$, caso 1); “Um professor reflexivo, que é aquele que eu procuro ser, é aquele que pensa constantemente sobre a sua prática, pensa e repensa os seus sucessos e os seus fracassos, aproveitando a reflexão para ajustar estratégias" (prof. $\mathrm{F}, 1^{\circ}$ ciclo do EB, caso 2).

A aquisição de conhecimentos na FPG traduz-se num maior domínio, profundidade e rigor científico com que o professor ensina e exemplifica certos conteúdos: "sinto que a própria tarefa me exige maior conhecimento e maior domínio do conteúdo que estou a lecionar" (prof. E, $3^{\circ}$ ciclo do EB, caso 1); "eu consigo responder aos alunos de forma cientificamente correta" (prof. G, $2^{\circ}$ ciclo do EB, caso 2). Estes conhecimentos têm também reflexo no reconhecimento da credibilidade dos conhecimentos partilhados e das funções desempenhadas, resultando numa maior capacidade para interligar assuntos e aliar as componentes científica, técnica e pedagógica. Estes efeitos estão intimamente associados a outros relacionados com uma melhor preparação dos alunos e a um desempenho de qualidade do docente.

De acordo com os professores entrevistados, a frequência de cursos pós-graduados, de forma geral, tem ainda impacto na planificação das aulas revelando-se num maior cuidado na sua preparação e na capacidade de planear as aprendizagens dos alunos, "porque uma boa preparação, não quer dizer que depois não possamos mudar o plano e isso tudo e muitas vezes mudo, mas pensar o ensino, pensar a aula antes da aula é muito importante e melhora muito a qualidade da aula" (prof. F, $1^{\circ}$ ciclo do EB, caso 1 ). Possibilita também modificar as dinâmicas em sala de aula, a forma de olhar para as situações e para as pessoas e a forma como se ensina os alunos a olhar para as coisas a partir do desenvolvimento de capacidades e da aquisição de conhecimentos que permitem alargar horizontes. 
A FPG manifesta-se, na sala de aula, na vontade de aprofundar o trabalho realizado, numa maior capacidade de reflexão e numa maior consciência sobre o currículo em ação. Ao nível micro espelha-se, ainda, em mudanças nos professores como profissionais, num saber-fazer melhorado, numa experiência académica marcada por muitos acontecimentos que os preparam para uma resposta diferente quando determinadas situações acontecem na sala de aula.

A FPG tem consequências na forma como o docente motiva os alunos (e.g. "consigo falar e ir buscar exemplos com uma outra dimensão que não existiam caso não tivesse estas pós-graduações e isso motiva-os e desperta-lhes curiosidade" - prof. D, $2^{\circ}$ ciclo do EB, caso 2), assim como na forma como se relaciona com eles e os orienta, podendo, por vezes, ser visto como um exemplo a seguir (e.g. "Portanto eu estou a dar o exemplo de que nunca abandonei os livros, nunca abandonei a escola, mesmo sendo professor eu também sou aluno. Faço com que eles vejam em mim uma pessoa que quer mais. Quer mais como? Como aluno, porque ser aluno é ser capaz de aprender." - prof. F, $1^{\circ}$ ciclo do EB, caso 1 ).

Os professores que frequentam cursos pós-graduados consideram que essa frequência os torna, de modo geral, mais atentos, conscientes, rigorosos, tolerantes, sensíveis, competentes, responsáveis, organizados e confiantes. Os docentes com FPG evidenciam um maior à-vontade e um maior nível de reflexividade, preparação e capacidade de organização do grupo e das suas práticas no tempo e no espaço. Estes profissionais revelam ainda uma maior preocupação com a adequabilidade das práticas e com a necessidade de as melhorar. A investigação desenvolvida revelou ainda que os professores que contemplam FPG nas suas trajetórias têm melhores capacidades para resolver situações particulares e de integrar e de compreender melhor os alunos. Estes docentes criam, por vezes, uma ligação da sala de aula com o ensino superior, envolvendo os alunos em atividades da Universidade relacionadas, sobretudo, com a investigação, como é o caso de um professor que leciona no caso 1: 
Foram dois anos da minha vida que eu adorei onde fiz a ponte entre as minhas aulas aqui e a pós-graduação, com projetos até a nível europeu. Integrei um projeto e os meus alunos fizeram um trabalho excelente e foram apresentar o trabalho no Congresso de História e Filosofia das Ciências (prof. G, ensino secundário, caso 1).

\section{Impacto na Escola (meso - impacto)}

Os efeitos da FPG frequentada por docentes são, muitas vezes, questionados e há até quem duvide da existência destes efeitos na escola onde os professores pós-graduados prestam serviço, tal como afirma, por exemplo, um professor que desempenha funções no caso 1: "Para a escola não serve" (prof. $\mathrm{H}, 2^{\circ}$ ciclo do $\mathrm{EB}$, caso 1 ). Há quem defenda que não há qualquer efeito e ainda há quem assuma que estes efeitos poderão estar dependentes da área de formação, uma vez que "se a formação for feita em administração e gestão escolar, por exemplo, vai ajudar, mas se for numa outra área de formação que não esteja relacionada com o que se ensina nem com a organização escolar acho que não há impacto" (prof. H, $3^{\circ}$ ciclo do EB, caso 2). Com a investigação desenvolvida, percebemos que existe uma falta de aceitação ou reconhecimento pelos pares dos professores que foram mais além na sua formação, como é visível, por exemplo, através do discurso de um professor do caso 1:

Eu acho que os agrupamentos deveriam aproveitar os recursos humanos que têm às vezes nas escolas e não vê-los apenas como possíveis ameaças. Parece que alguns professores, uns são suprassumos, porque têm muitas formações, muitos mestrados, muitos doutoramentos e são os maiores do mundo, os outros têm algumas formações, mas podem tornar-se ameaças então deixa-os lá estar no cantinho para não chatearem (prof. E, $3^{\circ}$ ciclo do EB, caso 1 ).

No entanto, são muitas as situações, as atitudes, os comportamentos que revelam efeitos da FPG, tal como o desenvolvimento de características pessoais que acabam por ter implicações na escola, uma vez que, 
como defende um dos professores participante no estudo, "Eu acho que a melhor ação é aquela que resulta de uma vivência das teorias, ou seja, nós interiorizamos de alguma forma os nossos conhecimentos e depois praticamo-los" (prof. I, $1^{\circ}$ Ciclo do EB, caso 2). Os cursos pós-graduados frequentados por docentes permitiram a mobilização destes profissionais para cargos ou funções associadas à área de especialização como foi o caso de um professor participante que reconhece que "há colegas perfeitamente capazes de exercerem este cargo e [...] com capacidades igualmente boas ou até superiores para exercer o cargo e eu fui obrigada a exerce-lo precisamente por causa do mestrado" (prof. D, ensino secundário, caso 1).

Os efeitos da FPG revelam-se, como foi dito anteriormente, na valorização pessoal, na autoestima e na autoconfiança dos professores que tem impacto na instituição onde trabalham através de ideias mais consolidadas, de uma maior atenção face ao contexto, da forma de olhar para os alunos, das intervenções com alunos com necessidades educativas especiais e da mediação entre os pais e professores destes alunos, uma vez que "há um outro olhar talvez mais maduro, mais pensado sobre as coisas" (prof. G, $2^{\circ}$ ciclo do EB, caso 2). Os docentes com FPG são, segundo os respondentes, considerados mais eficazes na resolução de problemas, com uma maior capacidade de dar resposta a questões do dia-a-dia e com uma maior consciência dos problemas da prática profissional do ponto de vista da Organização, ideia corroborada, entre outros, por um dos professores que leciona no caso 1: "algumas das coisas que eu fui aprendendo revelam-se, digamos, como chaves para resolução de problemas que antigamente para mim não sabia como é que havia de resolver aquilo, e perceber alguns alunos" (prof. I, $2^{\circ}$ ciclo do EB, caso 1 ).

A realização de FPG tem, também, impacto no trabalho desenvolvido com os alunos, nas interações e relações estabelecidas, nos recursos utilizados em diferentes momentos, nas ações da escola e na adoção de diferentes formas de comunicação, como descreve um professor do caso 1: "A minha intervenção com os professores passa muito por aconselhamento de melhores formas de comunicar e de trabalhar com o aluno de acordo com a problemática. Dou aos professores orientações e 
aconselhamento de acordo com as problemáticas dos alunos" (prof. I, $2^{\circ}$ ciclo do EB, caso 1) e de um professor do caso 2 que afirma que "Alertei os colegas para outras maneiras de comunicar não só na sala de aula, mas fora da sala de aula e para utilizar outros recursos que a escola tem e tentar potenciar esses recursos" (prof. J, $1^{\circ}$ ciclo do EB, caso 2). Os cursos pós-graduados têm impacto na forma de ensinar os alunos a olhar para as coisas, na capacidade de justificar teoricamente as práticas realizadas até então de forma intuitiva, assim como na forma como os docentes articulam a teoria e a prática e na alteração do modo de trabalhar (e.g. "as atividades que faço têm sempre um porquê só que isto ajuda-me a encontrar melhor esses porquês. Eu consigo ver às vezes coisas que se calhar não via antes e achava que antes estavam certas e agora já vejo que não" - prof. $\mathrm{F}, 1^{\circ}$ ciclo do EB, caso 2). A FPG teve efeitos na relação entre a escola e a Universidade com a possibilidade de envolver os alunos da escola em projetos das instituições de ensino superior.

A FPG tem impactos, de forma direta, na relação com os pares, na forma como trabalham e nas dinâmicas que criam, tal como afirma um dos participantes "são pessoas com outras dinâmicas e com outras práticas letivas, porque estão muito mais abertas a coisas novas" (prof. $\mathrm{J}, 1^{\circ}$ ciclo do EB, caso 1 ). Os docentes com FPG revelam-se como pessoas estimulantes e motivadoras para os colegas, constituindo uma potencialidade na discussão e na partilha do conhecimento como refere um dos professores "eu sinto que muitas vezes faço aqui um trabalho de os meus colegas não quererem e eu dizer «Epah bora lá, não custa nada! Anda lá, eu ajudo ou faço»" (ibidem). Este conhecimento quando colocado ao serviço da escola poderá ser um benefício para o desempenho dos próprios colegas, principalmente através da disponibilização de materiais ao serviço do desenvolvimento profissional dos pares, das ações de formação e da partilha de conhecimentos em momentos informais, como descreve um professor "passo muitos destes conhecimentos aos colegas, porque tínhamos reuniões e falávamos das coisas e discutíamos e as pessoas ouviam-me e partilhava também muitos materiais e ainda partilho" (prof. K, ensino secundário, caso 1). Os efeitos da FPG dos 
professores na escola manifestam-se ainda na forma de trabalhar com os colegas, nos recursos utilizados no exercício de práticas específicas e no exemplo que são para aqueles com quem trabalham na escola. Os professores pós-graduados têm tendência para se tornarem, igualmente, profissionais mais disponíveis para ajudar e apoiar os colegas, para promover o trabalho em equipe e para colaborar na instituição onde lecionam afirmando, a título de exemplo, um participante que "quando há partilha, faço, eu gosto de trabalhar em grupo e aí acho que é um benefício e posso, pedem e ajudo sempre toda a gente" (prof. $\mathrm{H}, 2^{\circ}$ ciclo do EB, caso 1) e outro que "os meus conhecimentos são postos primeiramente ao dispor do meu grupo de trabalho e aí os meus conhecimentos são disponibilizados" (prof. D, $2^{\circ}$ ciclo do EB, caso 2 ).

A análise dos dados recolhidos permite-nos considerar que com a realização de FPG, os professores conseguem um maior reconhecimento das suas competências, mais rigor nas diferentes ações na escola e maior qualidade nas suas diferentes práticas profissionais, justificando, neste contexto, um dos professores que "Eu tenho um maior grau de exigência com aquilo que leio, com aquilo que escrevo. Tornei-me mais rigoroso com o trabalho que desenvolvo" (prof. L, ensino secundário, caso 1). Estes profissionais apresentam-se com uma mente mais aberta, mais disponíveis para colaborar na e com a escola, para desempenhar um papel ativo no desenvolvimento e fundamentação de projetos e ações e para serem mais competentes, mais exigentes, mais eficazes, com uma maior capacidade reflexiva e de adaptação e com uma maior atitude científica (e.g. "sou mais exigente na produção de documentos, sou um profissional mais exigente com os outros também" - ibidem; "um nível de exigência que eu não teria caso eu não tivesse feito esse tipo de trabalho" - prof. A, $3^{\circ}$ ciclo do EB, caso 1; "sei porquê que faço assim e sou capaz de explicar aos meus colegas porquê que faço assim" - prof. C, $3^{\circ}$ ciclo do EB, caso 2 ). Os docentes pós-graduados são, tendencialmente, mais dedicados, com maior capacidade para a tomada de decisão, com uma intervenção mais refletida, com atitude crítica e com grande capacidade de adaptação (e.g. "há um outro olhar talvez mais maduro, mais pensado sobre as coisas" - prof. D, $2^{\circ}$ 
ciclo do EB, caso 2; "com o espírito de exigência, o olhar crítico e com uma melhor capacidade de reflexão que imprimi, penso eu, no mestrado depois repercutiu-se para as diferentes áreas do meu desempenho" - prof. I, $2^{\circ}$ ciclo do EB, caso 1 ).

O impacto da FPG dos professores verifica-se também ao nível meso na forma de estar, na atenção dada a determinadas questões, na tomada de consciência do espaço de atuação e na visão de escola fazendo com que, por exemplo no caso 1, "as pessoas todas acabam por perceber que aqui se trabalha um bocadinho de uma maneira diferente e eu penso que é reflexo disso" (prof. $\mathrm{M}, 1^{\circ}$ ciclo do $\mathrm{EB}$, no caso 1 ).

A realização de FPG ajuda os docentes na fundamentação de certas ações na escola, na compreensão das diretrizes pelas quais se rege e dos respetivos procedimentos como refere um professor participante "hoje sento-me e explico exatamente porquê que é assim e explico com base nos fundamentos teóricos e dos fundamentos legais [...] Dá-nos uma consciência nítida do que é o nosso espaço de manobra, o nosso espaço de atuação" (prof. L, ensino secundário, caso 1). Esta formação poderá, em último caso, ser um contributo para a escola com a realização de trabalhos académicos de natureza investigativa tendo a escola como campo de ação, tal como os professores pós-graduados constituírem influências que ao longo do tempo poderão levar a mudanças positivas das instituições escolares (e.g. "é importante envolver as nossas escolas em trabalhos de investigação, porque isso ajuda-nos a identificar problemas e a superá-los" - prof. F, $1^{\circ}$ ciclo do EB, caso 2).

\section{Impacto nas práticas investigativas e educativas (macro-impacto)}

O macro-impacto, isto é, o impacto nas práticas investigativas e educativas, constitui o nível de análise que revela impactos menos significativos, mesmo sendo muitos os efeitos reconhecidos. Esta formação tem efeitos nas relações que os docentes estabelecem, nomeadamente com os 
pais, com os encarregados de educação e com a própria comunidade. A FPG traduz-se, também, no desenvolvimento de investigações e na sua divulgação aos níveis nacional e internacional, podendo mesmo resultar na publicação dos seus resultados como contributo para a comunidade científica, afirmando inclusive um dos professores que "Eu gosto muito da investigação científica e permitiu-me que fizesse investigação ao mais alto nível em determinada altura e que fosse mostrar essa investigação mesmo fora a nível internacional, fora do país, alguns artigos que estavam para sair eu fui apresenta-los pela Europa fora" (prof. B, ensino secundário, caso 1).

É estreita a relação entre este nível e o nível meso. Ao nível meso, a realização de cursos pós-graduados tem repercussões na forma como o professor que a frequentou dinamiza diferentes ações na escola quando estas são direcionadas para a comunidade, tal como na criação de recursos de acesso à comunidade onde são divulgados os trabalhos desenvolvidos na Universidade, como é o caso de um professor que "No meu blog eu crio materiais e eu tenho que estar muito segura daquilo que coloco online" (prof. G, $2^{\circ}$ ciclo do EB, caso 2). Os efeitos da FPG estão efetivamente muito associados à Universidade, revelando-se na colaboração com o ensino superior em atividades de apoio à docência ou à investigação, na realização de trabalhos dos alunos em parceria com a Universidade e no envolvimento destes em projetos da responsabilidade das próprias instituições de ensino superior. Poderá, ainda, manifestar-se na apresentação à comunidade destes projetos constituindo a Universidade um espaço de divulgação dos trabalhos feitos pelos e com os alunos (e.g. "Prestei alguma colaboração ainda no decurso desse mestrado lá na Faculdade de Ciências. Fiquei a participar em alguns seminários" - prof. O, ensino secundário, caso 1; "eu faço os trabalhos aqui com os alunos e depois vou com eles apresentar à Universidade” - prof. L, ensino secundário, caso 1).

O macro-impacto dos cursos pós-graduados frequentados pelos professores traduz-se também no desempenho de novas funções na comunidade fora do contexto escolar, assim como na possibilidade de integrarem e desenvolverem novos projetos e na colaboração com organismos de âmbito educativo externos à escola (e.g. "depois de ter feito o mestrado, de me 
ter sentido realizado pessoalmente, eu colaborei com a Paróquia da Tapada das Mercês dando explicação aos alunos que tinham dificuldades em filosofia, que tinham dificuldades a outros níveis, de português por exemplo" — ibidem; "faço parte de um departamento de educação a nível político e também de mulheres e digamos que é essencialmente nessa área que mobilizo esses conhecimentos" - prof. K, ensino secundário, caso 2).

O impacto da FPG surge ainda associado a características pessoais que fazem a diferença nas várias intervenções, visto que os docentes com FPG têm, tendencialmente, e segundo os entrevistados, uma forma diferente de encarar a comunidade, uma maior credibilidade e reconhecimento das suas competências por parte desta, uma maior exigência, um maior rigor no trabalho desenvolvido fora da escola e uma maior atenção ao meio:

Se calhar há um estar mais atento sempre. [...] Do ponto de vista cognitivo que é muito interessante e que depois nos obriga a ver com outros olho. Tem a ver com todos os aspetos da vida quer ao nível micro, meso, macro, tem a ver com a maneira como olhamos a comunidade, como sentimos a comunidade, como percebemos os interesses da comunidade, como articulamos tudo isso de modo a defender um bocadinho os interesses do agrupamento. (prof. I, $1^{\circ}$ ciclo do EB, caso 1 ).

\section{Considerações finais}

A investigação realizada permitiu-nos, através da recolha de dados de natureza empírica, compreender as percepções dos professores pós-graduados sobre o impacto da FPG frequentada nos diferentes níveis de análise. Mesmo não tendo sido identificados pelos entrevistados efeitos negativos da FPG nos diferentes níveis, importa perceber que esta formação poderá ter, de acordo com a realidade, com as situações e com a área de formação impacto nulo num ou vários níveis.

Sem haver evidências da existência de impacto negativo da frequência de cursos pós-graduados, estes são vistos como um valor 
acrescentado para aqueles que obtêm diplomas de pós-graduação, mestrado ou doutoramento. Os docentes com FPG são assumidos como uma vantagem para aqueles com quem trabalham, para as instituições onde exercem funções, para os alunos e para a própria comunidade. No entanto, o impacto reconhecido das FPG não é somente positivo nem reconhecido imediatamente, quer por aqueles que as frequentaram quer por líderes e gestores escolares. Contudo, a investigação comprovou a existência de inúmeras competências e vantagens consequentes da FPG.

Verificamos, com o estudo realizado, a existência de uma reduzida menção a implicação nas aprendizagens dos alunos, visto que as formações frequentadas pelos inquiridos não têm como objetivo central, na maioria dos casos, a aprendizagem, uma vez que não se trata de formações realizadas nem na área científica disciplinar, nem na didática específica. Esta realidade será, posteriormente, revelada e debatida em outras publicações dedicadas a essas questões.

Quando falamos de formação de professores, quer seja pós-graduada quer não, somos levados a falar de alunos e das suas aprendizagens. Apesar de, na sua maioria, a FPG frequentada por professores não revelar efeitos diretos nas aprendizagens dos alunos, conseguimos identificar algumas influências indiretas. A FPG tem efeitos na alteração e adoção de novos recursos e estratégias de ensino e de aprendizagem, diferentes formas de transmitir conhecimentos, conhecimentos mais consolidados e profundos, por exemplo, que tem seguramente consequências nas aprendizagens dos alunos. No entanto, não podemos afirmar que aqueles que são ensinados por docentes com FPG têm melhores resultados, mas sim que estes alunos têm ao seu dispor mais ferramentas que os podem conduzir ao sucesso.

Inerente a toda a investigação esteve a necessidade de apresentar recomendações fundamentadas às instituições com responsabilidade na pós-graduação, ou seja, às Universidades que oferecem cursos pós-graduados e às escolas onde exercem funções os docentes com FPG. Foi nossa intenção que estas recomendações servissem de fundamento para uma reflexão aquando da conceção de cursos pós-graduados frequentados por 
professores do EB e do ES, de forma a potenciar o seu impacto nas escolas e a serem rentabilizados pelos órgãos de gestão.

Para as instituições universitárias recomendamos que se tome consciência das implicações que uma boa ou má formação poderá ter no desenvolvimento dos profissionais docentes, nas suas práticas e em último caso nas aprendizagens dos alunos; que se preste atenção à realidade, construindo currículos à medida das necessidades dos professores e que se procure perceber, junto do campo de atuação - EB e ES - a realidade, de forma a conseguir dar respostas adequadas a esta. Propomos, ainda, que se promova uma aproximação da Universidade às escolas.

Para as escolas, e consideramos aqui também as direções, sugerimos que conheçam e façam por conhecer quem são os docentes pós-graduados que desempenham funções nas suas instituições; que compreendam que formações realizaram e o que estas implicam atendendo ao valor acrescentado que poderão ter. Sugerimos que envolvam estes docentes em ações dentro e fora da escola, permitindo-lhes colocar o seu saber em ação ao serviço da escola, dos alunos e da própria comunidade educativa. Propomos também às escolas que sejam criadas condições para que os professores possam, sem sobrecargas de trabalho e de burocracias, frequentar cursos pós-graduados, assumindo-o como um investimento não apenas do professor, mas da própria escola que terá repercussões e que se mobilizem os docentes para cargos ou funções de acordo com as suas competências. Sugerimos ainda às escolas, compreendendo as suas direções, que conheçam, que se empenhem, que não tenham receio do trabalho que dá mudar estruturas e, se for preciso repensar a estrutura da própria escola que o façam.

No entanto, com o decorrer da investigação percebemos que estas recomendações se poderão alargar à Tutela e às políticas de educação e neste âmbito as nossas sugestões vão precisamente no sentido da criação de incentivos através de bolsas, licenças sabáticas e dispensas de serviço, mas também que se retomem as bonificações com efeitos na carreira, mesmo correndo o risco de que esta seja a maior motivação para uma "corrida às pós-graduações", mas não esquecendo que qualquer que seja 
a motivação, está em causa a aquisição de mais conhecimentos que poderão beneficiar a educação em Portugal. Pode-se levantar neste contexto a questão "Mas há garantias de que as competências consequentes das FPG sejam devidamente mobilizadas para as instituições onde estes docentes prestam serviço?", a resposta é "Não!”. Não há garantias de que as competências sejam todas mobilizadas ao serviço da escola, dos alunos, da comunidade, mas pelos dados recolhidos há sempre efeitos, muitos ou poucos, mas mais certamente do que a entrega ao comodismo e à estagnação. Propomos que se peçam contas às escolas sobre o desempenho dos docentes de acordo com a formação realizada e que se façam propostas de rentabilização e até de mobilização destes profissionais para diferentes organismos educativos.

Sugerimos, por fim, que se aposte na educação e não nos referimos apenas à educação de crianças e jovens nem à formação profissional, falamos da formação universitária, da FPG não com o intuito de formar e exportar quadros, mas de forma a qualificar os nossos profissionais para que se assista de facto a um ensino de qualidade. Não basta olhar para os rankings e questionar porque é que a educação noutros países é melhor; é preciso fazer mais, é preciso apostar e mudar, é preciso olhar para as questões de fundo e a formação dos professores é cada vez uma questão de fundo no contexto educativo.

\section{Referências}

CAMPOS, B. Formação contínua e pós-graduação de professores em Portugal. In: GOMEZ, J.; BAPTISTA, V. (Ed.). Educar, sem fronteiras/Educar sin fronteras. Universidades de Huelva e Faro, 1995. p. 145-160.

CARR, W. Reconstructing the curriculum debate: as editorial introduction. Curriculum Studies, v. 1, n. 1, p. 5-9. 1993. 
COHEN, L.; MANION, L.; MORRISON, K. Research Methods in Education. 5. ed. London: RoutledgeFalmer, 2006.

CRUZ, E.; POMBO, L.; COSTA, N. Dez anos (1997-2007) de estudos sobre o impacto de cursos de mestrado nas práticas de professores de ciências em Portugal. Revista Brasileira de Pesquisa em Educação em Ciências, v. 8, n. 1, s.p. 2008.

CUNHA, A. Ser professor: bases de uma sistematização teórica. Braga: Casa do Professor, 2008.

DOYLE, W. Curriculum and pedagogy. In: JACKSON, PH. Handbook of Research on Curriculum. New York: Macmillan Library Reference USA, 1992. p. 486-516.

ESTRELA, M. T. Complexidade da epistemologia do currículo. In: LEITE, C.; PACHECO, J.; MOREIRA, A.; MOURAZ, A. (Orgs.). Políticas, Fundamentos e Práticas do Currículo. Porto: Porto Editora, 2011. p. 29-36.

FERNANDES, D. Acerca da articulação de perspectivas e da construção teórica em avaliação educacional. In: AFONSO, A.; ESTEBAN, M. (Orgs.). Olhares e interfaces - reflexões críticas sobre a avaliação. São Paulo: Cortez Editora, 2010. p. 15-44.

GRESS, J.; PURPEL, D. (Ed.). Curriculum: an introduction to the field. United States of America: Clutchan Publishing Corporation, 1978.

JESUS, A. Currículo e educação: conceito e questões no contexto educacional. [S.I.], 2008. Disponível em: <http://www.pucpr.br/eventos/educere/educere2008/anais/pdf/642_840.pdf>. Acesso em: 21 out. 2016.

LEITE, C. Percursos e tendências recentes da formação de professores em Portugal. Educação, Porto Alegre, v. 57, n. 3, p. 371-389, set./dez. 2005.

LEITE, C. A formação de professores em Portugal e a Declaração de Bolonha. [S.I.], n.d. Disponível em: <http://paco.ua.pt/common/bin/Bolonha/BOLONHA _A\%20Forma\%C3\%A7\%C3\%A3o\%20Professores\%20em\%20Portugal\%20 Prof.\% 20Carlinda\%20Leite.pdf >. Acesso em: 20 out. 2016.

LESSARD-HÉBERT, M.; GOYETTE, G.; BOUTIN, G. Investigação Qualitativa: Fundamentos e Práticas. 2. ed. Lisboa: Epistemologia e Sociedade, 2005. 
LEWIS, S. Curriculum planinning for better teaching and learning. (4. ed.). United States of America: Holt, Rinehart and Winston, 1902.

PACHECO, J. Teoria curriculares: políticas, lógicas e processos de regulação regional das práticas curriculares. In: SEMINÁRIO "O CURRÍCULO REGIONAL", Açores, 2003. Disponível em: <http://webs.ie.uminho.pt/jpacheco/files/curriculoRegional.pdf $>$. Acesso em: 21 out. 2016.

PERALTA, M. H. Currículo: o plano como texto - Um estudo sobre a aprendizagem da planificação na formação inicial de professores de alemão. Lisboa: Fundação Calouste Gulbenkian e Fundação para a Ciência e Tecnologia, 2005.

PEREIRA, G.; COSTA, N. A construção de conceitos sobre avaliação do impacto da formação: um primeiro passo para a aç̧ão. In: XIII ${ }^{\circ}$ COLÓQUIO DA SECÇÃO PORTUGUESA DA AFIRSE: REGULAÇÃO DA EDUCAÇÃO E ECONOMIA ORGANIZAÇÃO, FINANCIAMENTO E GESTÃO, 2004, Lisboa. Atas XIII ${ }^{\circ}$ Colóquio da Secção Portuguesa da AFIRSE: Regulação da Educação e Economia - Organização, Financiamento e Gestão. Lisboa: Faculdade de Psicologia e de Ciências da Educação da Universidade de Lisboa, 2005.

POMBO, L.; COSTA, N. Avaliação de impacte de cursos de mestrado nas práticas profissionais de professores de ciências - Exemplos de boas práticas. Investigações em Ensino das Ciências, v. 14, n. 1, p. 83-99, 2009.

POUZADA, A.; MARTINS, M.; LUCAS, C.; CABRAL, D.; CRISTINO, J. Articulação formação graduada - formação pós-graduada: Uma proposta de reflexão para o Conselho Académico da Universidade do Minho. [S.I.], 2003. Disponível em: 〈http://www.cac.uminho.pt/docs/ gp-fgpg.pdf >. Acesso em: 21 out. 2016.

ROLDÃO, M. Gestão curricular - fundamentos e práticas. Lisboa: Ministério da Educação - Departamento de Educação Básica, 1999.

ROLDÃO, M. (Coord.). Formação e práticas de gestão curricular. Crenças e equívocos. Porto: Edições ASA, 2005.

ROLDÃO, M. et al. Avaliação do impacto da formação: um estudo dos Centros de Formação da Lezíria e Médio Tejo 1993-1998. Lisboa: Edições Colibri, 2000. 
SACRISTÁN, J. O currículo: uma reflexão sobre a prática. 3. ed. Porto Alegre: Artmed, 2000.

ZABALZA, M. Planificação e desenvolvimento curricular na escola. 6. ed. Porto: ASA Editores, 2001.

Recebido: 10/11/2016

Received: 11/10/2016

Aprovado: 05/05/2017

Approved: 05/05/2017 